\title{
Escribir a la sombra de otro idioma: escritores latinoamericanos mantienen el Español en los Estados Unidos
}

Johanny Vázquez Paz

Follow this and additional works at: https://digitalcommons.usf.edu/surcosur

Part of the Bilingual, Multilingual, and Multicultural Education Commons, Creative Writing Commons, Critical and Cultural Studies Commons, and the Latin American Languages and Societies Commons

\section{Recommended Citation}

Vázquez Paz, Johanny. 2011. Escribir a la sombra de otro idioma: escritores latinoamericanos mantienen el Español en los Estados Unidos. Revista Surco Sur, Vol. 2: Iss. 4, 31-35.

DOI: http://dx.doi.org/10.5038/2157-5231.2.4.12

Available at: https://digitalcommons.usf.edu/surcosur/vol2/iss4/12

This CRITERIO ATENTO is brought to you for free and open access by the Open Access Journals at Digital Commons@ University of South Florida. It has been accepted for inclusion in Revista Surco Sur by an authorized editor of Digital Commons @ University of South Florida. For more information, please contact digitalcommons@usf.edu. 


\section{Johanny Vázquez Paz}

La escritora argentina residente en Chicago, Leda Schiavo, señaló que:

Escribir en la lengua de uno en el país del otro es signo de afirmación o de locura, de amor o de odio, de soledad o solidaridad, de regodeo o indiferencia, de atrevimiento o cobardía, de fijación en el pasado o deseo de porvenir, de ardiente fe o nihilismo. (Rangel, Preámbulo)

Emigrar es buscar un nuevo espacio donde vivir, dejar lo conocido por voluntad propia para empezar una nueva vida en otra parte del mundo. Entonces, ¿por qué no despedirse también del idioma y adoptar la lengua que ahora nos rodea? $Y$ si se es escritor, ¿por qué insistir en escribir en un idioma que limita al tratar de publicar en el país donde se reside?, ¿por qué escribir en español cuando se vive en Estados Unidos? Éstas son algunas de las preguntas que exploraré en este ensayo, desde perspectivas descritas por escritores reconocidos, proponiendo posibles causas y motivos y examinando el movimiento cultural y literario que se da en español en la ciudad de Chicago, donde se escribe y se publica en castellano. Desde luego que al principio la razón de escribir en español es obvia: no se domina el inglés lo suficiente como para hacerlo en esa lengua. Pero pasado el tiempo los dos idiomas se vuelven uno, y ambos se entienden con la misma facilidad y salen de la boca con el mismo dominio. Entonces, ¿por qué no facilitarnos la carrera cuando el lugar del maratón que corremos es en inglés?

Una de las razones más obvias que tienen los que escriben en español, residiendo en Estados Unidos, es el amor a su lengua materna y la conexión que ésta le brinda con el país natal. Gioconda Belli en su discurso de ingreso a la Real Academia de la Lengua menciona:

Yo soy nicaragüense y desde que partí no hago más que vivir en un país imaginario. Este país con su textura de algodón, su olor a café y tierra mojada, lo convoco a diario cuando exorcizo la lengua extranjera y escribo en el único idioma en el que soy yo misma. El español me rodea entonces con sus penínsulas, sus golfos y sus bahías y en esa geografía atraco mi barco y paso del naufragio a la salvación.

Para Belli el idioma es su salvación porque la hace sentir que no ha perdido su pasado y la devuelve a su tierra aunque sea en la imaginación. Muchas veces les he dicho a mis amigos en la Isla, que vivo en un pueblo de Puerto Rico llamado Chicago, porque allí nos hemos construido "un mundo nuestro" en el barrio de Humboldt Park, y desde que entras te reciben unas banderas puertorriqueñas de metal, gigantes, señalando nuestro territorio de acera a acera. Este barrio puertorriqueño está lleno de mitos, como señala el crítico literario Efraín Barradas, quien dice que la escritura de los "autores que viven en los Estados Unidos (refiriéndose mayormente a los poetas puertorriqueños)

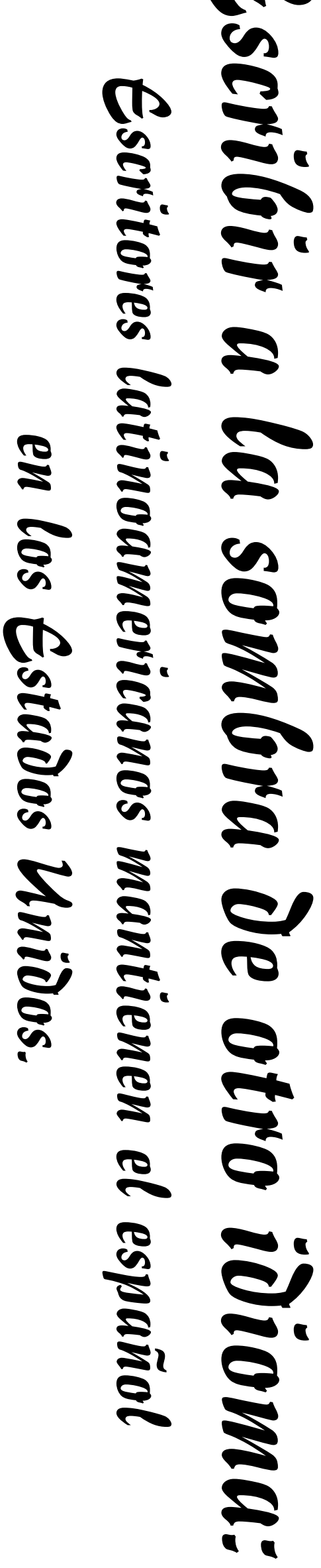



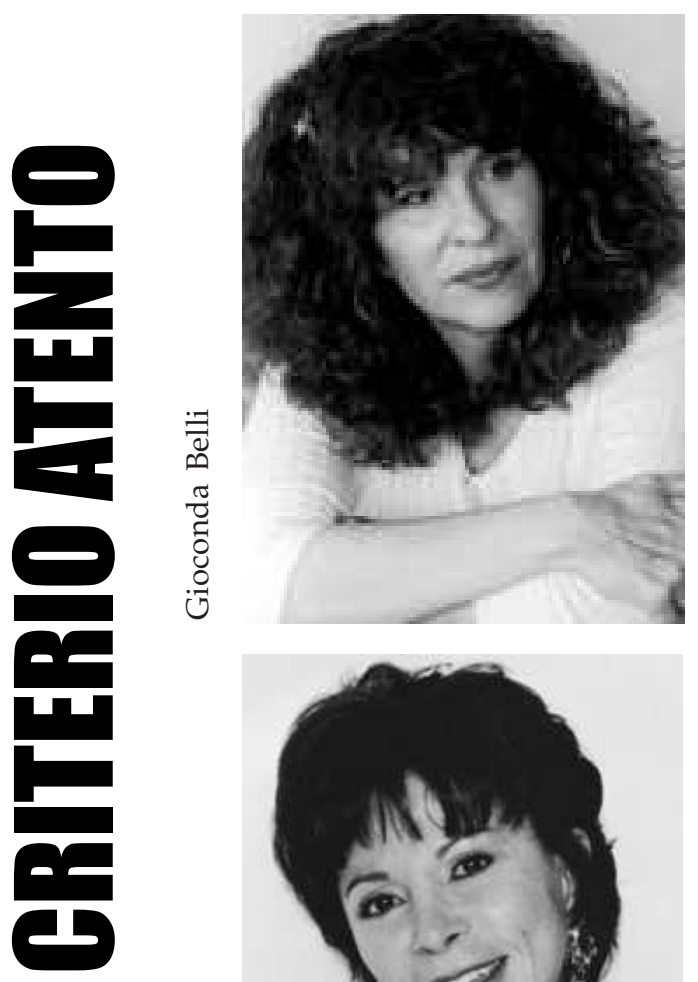

podría considerarse una lectura basada en los mitos que la sostienen" (Barradas, 47). Estos mitos no sólo se observan en la literatura y, probablemente el arte en general, sino que están presentes en las comunidades que han nacido en algunas ciudades de Estados Unidos, o, si no existen, se crean en los propios espacios de los inmigrantes que muchas veces llenan la casa de recordatorios artísticos o culturales de sus países natales.

Por esto, para una escritora como Isabel Allende, quien habla casi siempre en castellano con su esposo norteamericano, haciendo hincapié en que "[sus] raíces chilenas son fuertes" y solamente puede escribir en español y la cito: "para mí es un proceso muy orgánico que sólo puedo lograr en mi idioma". Además, señala que sigue escribiendo en español "porque en cada libro [...] trata como de entender cosas, de explorar partes de la vida [...] que están escondidas" (Wegsman, New York Daily News). Sin embargo, Allende admite que ahora escribe un español "simplificado por el inglés" porque éste le enseñó a escribir con un idioma más preciso.

Otro ejemplo es el escritor boliviano Edmundo Paz Soldán, quien lleva más de 20 años viviendo en los Estados Unidos. Aunque a Paz Soldán le han aconsejado que escriba en inglés, él señala en una entrevista lo siguiente: "[...] yo necesito sentirme parte de algo grande, y eso es, para mí, Bolivia y la literatura latinoamericana. En español tengo más matices al escribir, más comodidad". (Pajares C.)

Sin embargo, para escritores como Gioconda Belli, Isabel Allende, Edmundo Paz Soldán, Alicia Borinsky, Miguel Ángel Zapata, Jorge Kattán, Víctor Fuentes y el recientemente fallecido Tomás Eloy Martínez, entre otros, la decisión de escribir en español no es tan difícil porque, como señala Febronio Zatarain en su ensayo sobre revistas literarias en Chicago y en español:

[...] el inmigrante que ya llegó siendo escritor tiene sólo una preocupación fundamental: publicar, pues seguramente en su país ya [...] cuenta con un público y quizás con el apoyo de una casa editorial. (Zatarain, inédito)

O sea, que los escritores que ya han sido reconocidos en sus países de origen o en Latinoamérica y se mudan a los Estados Unidos, se pueden dar el lujo de continuar escribiendo en español porque ya tienen editoriales dispuestas a publicarlos, y muchas veces, inclusive, a traducirlos para poder mercadearlos mejor en ambos espacios.

Hay escritores que pueden saltar de un idioma a otro y a veces escriben en español y otras en inglés. Sus razones para escoger entre los idiomas dependen de la temática de lo que están escribiendo y del lector al cual quieran llegar. Para la poeta puertorriqueña Luz María Umpierre escribir en ambos idiomas es importante e indispensable y lo hace porque como ella dice:

[...] las audiencias son distintas. Si voy a dirigirme a gente en los Estados Unidos sobre algo que quiero denunciar, lo hago en inglés. Por otro lado, si creo que debo hablarle a Puerto Rico o a los Latin@s, entonces escribo en español.

El proceso, sin embargo, como ella misma señala, es muy complejo ya que: 
[...] depende a quién le escriba el poema, el idioma cambia; no porque yo los seleccione, sino [...] porque así me sale. Las temáticas eran distintas al principio [...] lo sexual me salía principalmente en inglés. Ahora, la temática en inglés se ha convertido en lo amoroso, pero cuando quiero expresar ternura lo quiero escribir en español. (Correspondencia personal con la autora).

Para el escritor mexicano Francisco Jiménez, quien llegó a los Estados Unidos con su familia cuando tenía apenas 4 años, la temática de lo que escribe influye en su decisión de en cuál idioma escribir. Si escribe algo sobre las experiencias de su niñez, lo hace en español; si escribe comentarios literarios o sociales, usa con más frecuencia el inglés. (Jiménez, Módulos Culturales)

La complejidad de este proceso también lo señala el escritor cubano residente en Miami, Gustavo Pérez Firmat, en los ensayos de "Cincuenta lecciones de exilio y desexilio". Para poder escribir estos ensayos en español, Pérez Firmat se dio a la tarea de cambiar su medio ambiente, moviendo los muebles de su oficina y lo justifica de la siguiente forma:

[...] he creído que los objetos, igual que las personas, igual que los lugares, tienen una nacionalidad. (Levine y Montross, 34)

Por eso, al "arrancarles" el nombre en inglés y "bautizarlos" en español, Pérez Firmat puede "imponerle cualquier idioma a cualquier lugar, a cualquier hogar" (Levine y Montross, 34) y de esta manera programarse mental y físicamente para escribir en un idioma que ni su familia ni la mayoría de la gente en donde vive habla.

Tenemos también el caso especial del escritor chicano Rolando Hinojosa. Aunque Hinojosa nació en los Estados Unidos, no sólo ha escrito muchos de sus libros en español, sino que su trabajo está influenciado por clásicos españoles y mantiene un "diálogo metaliterario con la literatura medieval española" en muchas de sus obras. (Zilles, Revista Paralelo Sur). Hinojosa fue el primer escritor estadounidense en obtener en 1976 el Premio Casa de las Américas, con su novela Klail City y sus alrededores. Estampas del valle, la serie de libros a la cual Klail City pertenece, no la tradujo al inglés el propio autor hasta 10 años después de haberse publicado el primer libro de la serie. Sin embargo, estas traducciones (o "recreaciones" como las llama el autor) pueden considerarse como libros apartes, diferentes al original por las muchas licencias que éste se tomó en inglés. Estas libertades no hubieran sido aceptables si las hubiera hecho un traductor común de obras literarias.

Para algunos escritores el cambiar de un idioma a otro resulta controversial y criticado. El mejor ejemplo de esto lo tenemos en la escritora puertorriqueña Rosario Ferré. En 1995 Ferré publicó la novela The House on the Lagoon, escrita originalmente en inglés. Esto fue recibido por muchos puertorriqueños como una traición a sus raíces y a la ideología independentista que decía apoyar al principio de su carrera. La escritora se defendió reclamando:

No soy menos puertorriqueña porque puedo escribir en inglés. ¿Por qué tengo que limitarme a un sólo idioma cuando puedo expresarme en ambos? ¿Por qué he de usar una sola mano cuando tengo dos? (The Puerto Rico Herald, Perfil de Puerto Rico: Rosario Ferré).
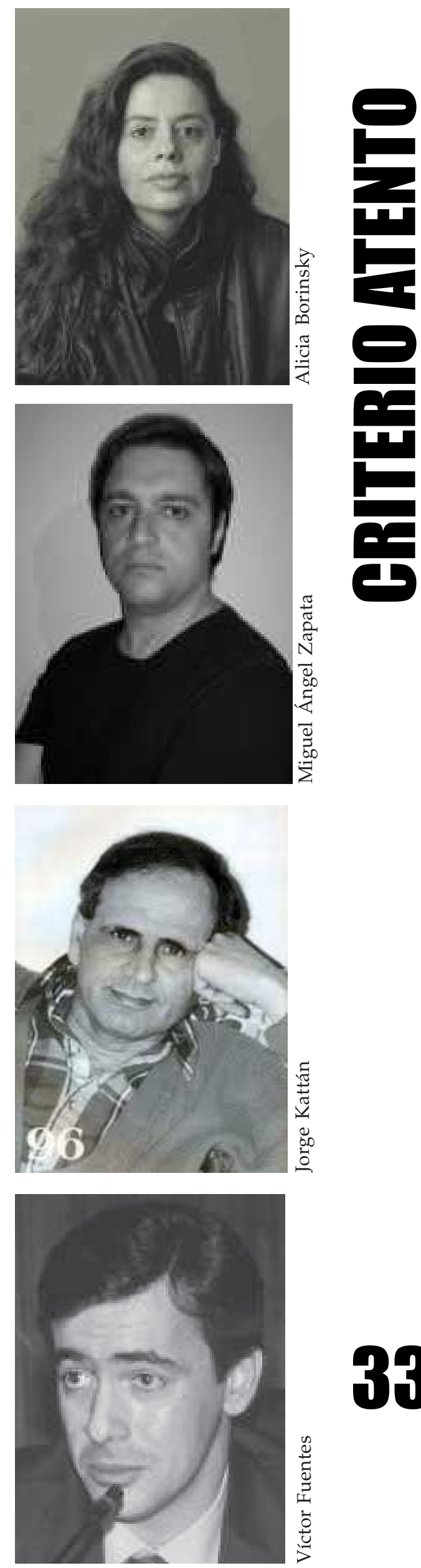

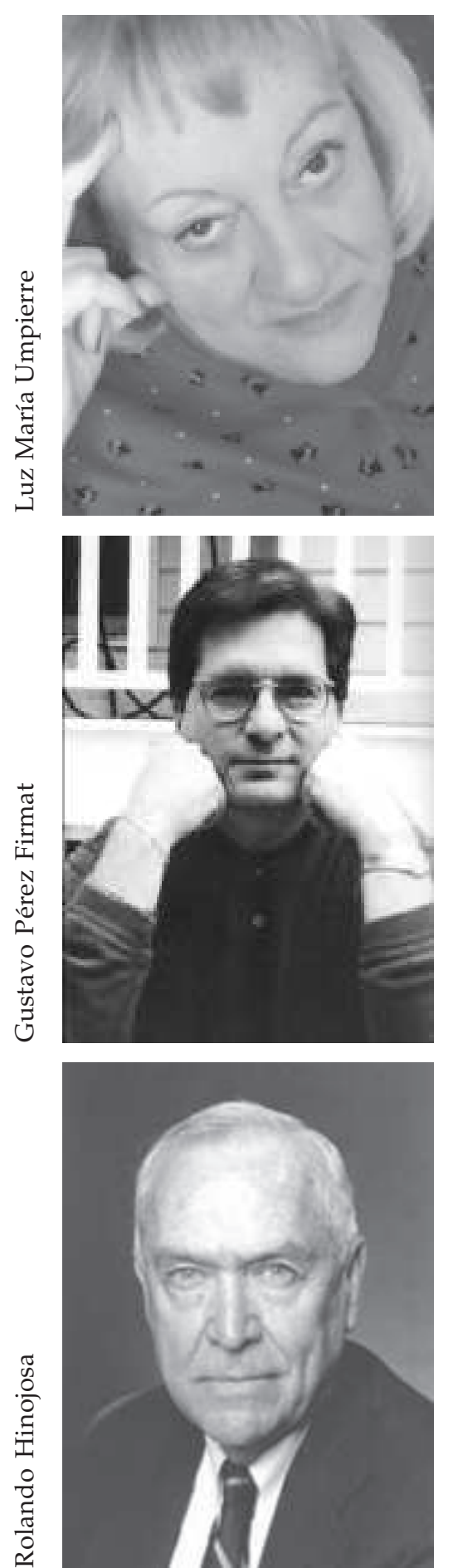
Es una aceptación del escritor de que su nuevo entorno es parte de su ser, mas no el todo; el convencimiento de que crear en español es de alguna manera su más fuerte recurso, el arma más poderosa para mantener su identidad. (Herrera, 39-40)

En la ciudad de Chicago esta resistencia lingüística se ha convertido en, como señala Herrera, "un movimiento real, sólido, y sobre todo de creciente calidad y variedad" (Herrera, 38). El más reciente resultado de este movimiento es la antología En la 18 a la 1, publicada por la editorial Vocesueltas. La antología incluye a catorce escritores de países como Cuba, Bolivia, Costa Rica, Perú, México, Puerto Rico e, inclusive Polonia, que escriben en español y se reúnen en un taller literario organizado por la revista Contratiempo. Este taller se convoca en el área mexicana de la calle 18, cada domingo a la una de la tarde. Todos los escritores incluidos escriben siempre en español (incluyendo al polaco que se enamoró de nuestra lengua) y solamente dos, curiosamente los dos puertorriqueños, han escrito, publicado y traducido algo de su trabajo al inglés. Como menciona Julio Ortega en el prólogo:

Son escritores, [...] y como tales manejan un discurso más complejo, no menos material ni cotidiano, sino más revelador de la subjetividad contemporánea; la cual ya no sólo es de los orígenes sino de los futuros, donde el español es una lengua internacional, que no discrimina sino que incorpora; y es por eso más moderna porque se nutre de la mezcla, y más humanista porque está hecha en el diálogo. (Ortega, x)

Es ese diálogo el que queremos mantener en español, no importa en qué país vivamos y cuáles otros idiomas hablemos. Muchos escritores residentes en Estados Unidos seguiremos escogiendo el español como nuestra herramienta de trabajo sea por razones sentimentales, o porque nos sentimos más cómodos al escribir en nuestra lengua materna, o porque hay ciertos temas que queremos discutir o exponer a otros hispanohablantes, o quizás porque sintamos temor hacia el difícil (como le dicen en Puerto Rico al inglés), o tal vez es porque, como dijo Julio Ortega: "[...] la lengua española ya no es extranjera y se [ha convertido] en un instrumento de construir el futuro". (Ortega, "Escribir español en Estados Unidos")

Un futuro que esperamos se reconozca en el mundo literario de las letras escritas en español, en un nuevo país latinoamericano llamado Estados Unidos.

\section{Bibliografía}

- Anzaldúa, Gloria. How To Tame A Wild Tongue. http://www.oppapers.com/essays/Tame-WildTongue/79724

- Barradas, Efraín. Partes de un todo: Ensayos y notas sobre literatura puertorriqueña en los Estados Unidos, San Juan: Editorial de la Universidad de Puerto Rico, 1998.

- Belli, Gioconda. Discurso de ingreso a la Real Academia de la Lengua. http:/ / www.giocondabelli.com/ conferencias/discurso\%20ingreso\%20RALE.htm - Ferré, Rosario. Language duel/ Duelo del lenguaje. New York, Vintage Books, 2002.

- Herrera, Jochy. Seducir los sentidos. Miami: Media Isla, 2010.

- Jiménez, Francisco. "Módulos Culturales: Paso IBiografia". Darthmouth University, 2001. http:// www.dartmouth.edu/ spanmod/modulos/ cajas/bio.html

- Levine, Esther L. y Constance M. Montross. Vistas y voces latinas. New Jersey: Prentice Hall, 2002.

- Ortega, Julio. Prólogo. En la 18 a la 1. Chicago: Ediciones Vocesueltas, 2010.

. "Escribir español en Estados Unidos". http:/ / congresosdelalengua.es/valladolid ponencias/unidad_diversidad_del_espanol/ 3_el_espanol_en_los_EEUU.

- Pajares C., Gonzalo. "Yo escribo en español, para el inglés me queda el ensayo": Entrevista a Edmundo Paz Soldán. http:/ / peru21.pe/impresa/noticia/yoescribo-espanol-ingles-me-queda-ensayo/201007-22/280594

- Rangel, Julio, editor. Preámbulo. Vocesueltas, cuatro cuentistas de Chicago. Chicago: Ediciones Vocesueltas, 2007.

- [Sin autor]. "Perfil de Puerto Rico: Rosario Ferré". The Puerto Rico Herald, 3 de agosto de 2001. http:/ /www.sololiteratura.com/fer/ferperfilde.htm

- Wegsman, Graciela Berger. "Entrevista: Isabel Allende entre la inmigración y el exilio". Periódico New York Daily News, edición virtual, 13 de mayo de 2009. http:/ / www.nydailynews.com/latino/espanol/ 2009/05/14/2009-05-14-isabel_allende_entre_ imaginacion_y_exilio.html.

- Zatarain, Febronio. "Revistas literarias en español en Chicago". Ensayo inédito facilitado por el autor.

- Zilles, Klaus. "Experimentación narrativa y diversidad lingüística en la obra de Rolando Hinojosa". Revista Paralelo Sur, Número 3, 2005. 